\title{
INFUSÃO DE ALOYSIA TRIPHYLLA: EFEITOS OPOSTOS EM UM TESTE DE ATIVIDADE ANTIOXIDANTE IN VITRO E NA ESTABILIDADE OXIDATIVA DE PATÊS DE PESCADO REFRIGERADOS
}

\author{
LAUREN FRESINGHELLI FERREIRA* \\ ANA PAULA DANIEL** \\ JAQUELINE PICCOLO*** \\ BRUNA KLEIN ${ }^{* * * *}$ \\ AMANDA ROGGIA RUVIARO**** \\ TATIANA EMANUELLI*****
}

\begin{abstract}
O objetivo deste trabalho foi avaliar o efeito da infusão de Aloysia triphylla (IAT) sobre os valores de $\mathrm{pH}$ e a estabilidade oxidativa de patês de carne de jundiá (Rhamdia quelen) armazenados refrigerados. A IAT apresentou $1,8 \mathrm{mg}$ de fenólicos totais $/ \mathrm{mL}$ e teve boa capacidade antioxidante no ensaio de remoção do radical 2,2-difenil-1-picrilhidrazila (DPPH) (equivalente a uma solução 3,2 $\mathrm{mM}$ de trolox). As formulações de patês, sendo uma controle (água) e três formulações com quantidades crescentes de IAT (18 mg, 45 $\mathrm{mg}$ e $90 \mathrm{mg}$ de fenólicos totais/kg de patê) foram armazenadas a $5^{\circ} \mathrm{C}$ e avaliadas ao longo de 28 dias quanto ao pH, oxidação lipídica (substâncias reativas ao ácido tiobarbitúrico, TBARS) e proteica (carbonilação de proteínas) e cor instrumental (CIELab). Os valores de $\mathrm{pH}$ reduziram ao longo da armazenagem, enquanto os de TBARS aumentaram até o $9^{\circ}$ dia e depois reduziram $(p<0.05)$, mas nenhuma dessas medidas foi influenciada pela IAT $(p<0,05)$. A oxidação proteica aumentou ao longo do armazenamento $(p<0.05)$

e as formulações com $45 \mathrm{mg}$ e $90 \mathrm{mg}$ de fenólicos/kg tiveram maior carbonilação proteica que o controle nos dias 21 e 28 de armazenagem, respectivamente $(p<0,05)$. Comparadas ao controle, as formulações com IAT tiveram maiores valores de $L^{*}$ no início da armazenagem e menores valores de $a^{*}$ e croma a partir do $15^{\circ}$ dia de armazenagem $(p<0,05)$. A IAT não foi efetiva como antioxidante em patês de jundiá, ainda que tenha apresentado boa atividade antioxidante no ensaio de remoção do radical DPPH in vitro.
\end{abstract}

PALAVRAS-CHAVE: ANTIOXIDANTE; POLIFENOIS; OXIDAÇÃO LIPÍDICA; OXIDAÇÃO PROTEICA; COR.

* Farmacêutica, mestranda em Ciência e Tecnologia de Alimentos do Programa de Pós-graduação em Ciência e Tecnologia dos Alimentos, Centro de Ciências Rurais, Universidade Federal de Santa Maria, Camobi, 97105-900,(UFSM) Santa Maria, RS, Brasil (e-mail: laurenfferreira@hotmail.com).

** Doutora em Ciência e Tecnologia dos Alimentos, professora do Colégio Politécnico da Universidade Federal de Santa Maria, Camobi, 97105-900,(UFSM) Santa Maria, RS, Brasil (e-mail: anapauladaniel@gmail.com).

*** Doutora em Ciência e Tecnologia dos Alimentos, Universidade Federal de Santa Maria, Camobi, 97105-900,(UFSM) Santa Maria, RS, Brasil (e-mail: jaquelinepiccolo@gmail.com).

**** Tecnóloga em Alimentos e Farmacêutica, mestrandas em Ciência e Tecnologia dos Alimentos, Universidade Federal de Santa Maria, Camobi, 97105-900,(UFSM) Santa Maria, RS, Brasil (e-mail: brunaklein06@yahoo.com.br; amandarruviaro@gmail.com)

***** Doutora em Ciências Biológicas (Bioquímica), professora associada IV do Departamento de Tecnologia e Ciência dos Alimentos, Universidade Federal de Santa Maria (UFSM), Santa Maria, RS, Brasil. (e-mail: tatiemanuell@gmail.com). 


\section{INTRODUÇÃO}

Os antioxidantes naturais vêm despertando grande interesse na medicina preventiva e na indústria de alimentos, representando uma alternativa promissora para a substituição de antioxidantes sintéticos convencionais (VALENTÃO et al., 2002; VEECK et al., 2013a; 2013b). Alguns desses compostos sintéticos apresentaram evidências de efeito carcinogênico em modelos com roedores, o gerou preocupação ainda que a relevância desse efeito para humanos não esteja totalmente esclarecida (BOTTERWECK et al., 2000).

A Aloysia triphylla (L'Her.) Britton, da família Verbenaceae, é uma planta medicinal, também utilizada como tempero (FUNES, et al. 2009). No Brasil, ela é conhecida como: cidró, cidrão ou limonete (VALENTÃO et al., 2002; FLORA DIGITAL, 2010). As folhas da A. triphylla possuem propriedades digestivas, antiespasmódicas, antipiréticas, sedativas e estomacais. Além disso, o seu óleo essencial foi patenteado para uso como anestésico durante o manejo de peixes (PI0904839-1 A2) e seu uso pré-abate prolongou a vida útil de pescados inteiros armazenados sob refrigeração (DANIEL et al., 2014). Tradicionalmente, sua infusão é utilizada no tratamento de asma, febre, flatulência, cólica, diarreia e indigestão (VALENTÃO et al., 2002). A infusão de A. triphylla (IAT) apresenta como principais constituintes compostos fenólicos, com destaque para os polifenóis (675 $\mathrm{mg} / \mathrm{L}$ ), como o verbascosídeo (400 mg/L) e a luteolina 7-diglicuronídeo (100 mg/L), bem como o óleo essencial rico em citral (CARNAT et al.,1999). Vaquero et al. (2010) comprovaram que existe uma forte correlação entre a quantidade de compostos fenólicos em extratos aquosos de $A$. citriodora a sua capacidade antioxidante avaliada como a capacidade de inibir a peroxidação lipídica, impedir danos oxidativos no DNA e remover espécies reativas de oxigênio (EROs).

A oxidação lipídica é uma das principais causas de deterioração e perda de qualidade dos alimentos. Trata-se de uma reação em cadeia, constituída pelas fases de iniciação, propagação e terminação, e que envolve a produção de radicais livres (CHAIJAN, 2008). Ela pode ser influenciada por fatores como a concentração de pró-oxidantes, enzimas, $\mathrm{pH}$, temperatura e a composição de ácidos graxos poli-insaturados da carne (CHAIJAN, 2008). Devido ao fato da carne de pescado conter grande quantidade de ácidos graxos poli-insaturados, ela é particularmente sensível a oxidação lipídica, que resulta em mudanças na cor, odor, textura e valor nutritivo do alimento (FOGAÇA et al., 2009). Dessa forma, os produtos de pescado constituem excelentes modelos para o estudo de aditivos antioxidantes. A oxidação lipídica acompanhada através da quantificação das substâncias reativas ao ácido tiobarbitúrico (TBARS) que constituem produtos secundários desta reação, especialmente o malonaldeído (JARDINE et al, 2002). As EROs estão envolvidas também na oxidação das proteínas. Os mecanismos da oxidação proteica são muito semelhantes aos da oxidação lipídica, e em alimentos processados a oxidação proteica leva a alterações na hidrofobicidade da proteína, reduzindo sua capacidade de retenção de água e alterando a textura do produto (LUND et al., 2011).

Os pescados são fonte importante de proteínas e contêm alta proporção de ácidos graxos poli-insaturados $n-3$, que possuem papel fisiológico importante para o desenvolvimento neural além de apresentarem efeitos cognitivos e neuroprotetores (YURKO-MAURO, 2010; TREVIZOL et al., 2013). A carne de pescado é um alimento saudável e ao mesmo tempo funcional, tornando-se cada vez mais importante a sua presença na dieta, uma vez que é a principal fonte de ácidos graxos n-3 de cadeia longa (FOGAÇA et al., 2009; RUFF et al., 2003; ZAMARIA, 2004). Os patês de pescado permitem o aproveitamento de resíduos da filetagem do pescado, tornando-se uma fonte de nutrientes de baixo custo (MINOZZO e WASZCZYNSKYJ, 2007). Tais produtos ampliam a variedade de patês existentes no mercado, permitindo características sensoriais diferentes e os benefícios nutricionais obtidos com o uso do pescado como matéria-prima (MINOZZO, 2010).

O objetivo deste trabalho foi investigar o efeito da adição da IAT sobre a estabilidade de patês de pescado refrigerados, através da avaliação dos valores de $\mathrm{pH}$, oxidação lipídica e proteica, bem como alterações de cor dos patês ao longo da armazenagem. 


\section{MATERIAL E MÉTODOS}

\subsection{INFUSÃO DE ALOYSIA TRIPHYLLA (IAT)}

A planta A. triphylla (L' Her.) Britton foi coletada na cidade de Frederico Westphalen $\left(27^{\circ} 22\right.$ "S; $\left.53^{\circ} 25^{\prime} \mathrm{W}\right)$, Rio Grande do Sul, Brasil. A espécie foi identificada pelo botânico Dr. Gilberto Dolejal Zanetti (Departamento de Farmácia Industrial, UFSM) e foi depositada no herbário do Departamento de Biologia da UFSM (SMDB No. 11169). A elaboração da infusão foi de acordo com Zamorano-Ponce et al. (2006). As folhas e galhos in natura foram secos em temperatura ambiente $\left(25^{\circ} \mathrm{C} / 24 \mathrm{~h}\right)$ e após, quebrados em tamanhos menores e então misturados com água destilada fervente $(5 \mathrm{~g} / 100 \mathrm{~mL})$ em recipiente tampado. Após 15 min de maceração, a amostra foi filtrada, resultando na infusão $5 \%$. Foram determinados o conteúdo de compostos fenólicos totais (SINGLETON e ROSSI, 1965) e a atividade antioxidante, através da capacidade de remoção do radical 2,2-difenil-1-picrilhidrazila (DPPH) (BRAND-WILLIAMS et al., 1995), da infusão obtida.

\subsection{ELABORAÇÃO E ARMAZENAGEM DOS PATÊS}

Os jundiás (Rhamdia quelen) frescos foram obtidos no comércio local, lavados em água contendo $5 \mathrm{ppm}$ de cloro, descabeçados, eviscerados e filetados. Os músculos ventrais e a espinha dorsal (sem nadadeiras) foram tratados como resíduos do processo de filetagem e usados para preparar a polpa de resíduo de filetagem conforme descrito por Bochi et al. (2008). Os filés e a polpa de resíduo da filetagem foram embalados e mantidos a $-18^{\circ} \mathrm{C}$ até a sua utilização (aproximadamente 7 dias).

Foram preparadas 4 formulações de patês utilizando a polpa de resíduo da filetagem de jundiá, sendo uma formulação controle (formulação base) e três formulações contendo IAT (18 mg, $45 \mathrm{mg} \mathrm{e} 90 \mathrm{mg}$ de compostos fenólicos/ $\mathrm{kg}$ de patê) adicionada em substituição a água, conforme detalhado na Tabela 1. O fixador de cor (eritorbato de sódio) não foi adicionado em nenhuma formulação, para não influenciar nas medidas de cor ou no processo de oxidação, já que o objetivo do trabalho é avaliar a capacidade antioxidante da IAT. Levando em consideração o alto conteúdo de ácidos graxos trans da gordura vegetal hidrogenada e visando produzir um embutido mais saudável, optou-se pela sua substituição por óleo de soja. Todos os ingredientes foram triturados em um cutter, sendo adicionados sequencialmente, iniciando pelo filé e polpa até a obtenção da massa base de patê (MINOZZO, 2010). Após a elaboração das massas, estas foram transferidas para embalagens retráteis, cozidas a $74-76^{\circ} \mathrm{C}$, resfriadas com água fria $\left(5^{\circ} \mathrm{C}\right)$ e secas. Foram preparadas 3 repetições independentes para cada formulação de patê de pescado $(n=3)$, que foram armazenadas a $5 \pm 1^{\circ} \mathrm{C}$ para análise da sua estabilidade ao longo de 28 dias. Após 1, 9, 15, 21 e 28 dias de armazenagem foram retiradas amostras de cada uma das repetições de todas as formulações para avaliação do $\mathrm{pH}$, oxidação lipídica e proteica e avaliação da cor instrumental.

\subsection{ANÁLISE DOS PATÊS}

Os valores de $\mathrm{pH}$ foram determinados com aparelho digital medidor de $\mathrm{pH}$ (DMPH -2 Digimed) a temperatura ambiente, após homogeneização de $1 \mathrm{~g}$ de patê com $10 \mathrm{~mL}$ de água destilada, conforme descrito por Pastoriza \& Sampedro (1994).

O valor de TBARS foi determinado espectrofotometricamente como descrito por Buege \& Aust (1978), como indicador da oxidação lipídica. As amostras foram homogeneizadas com KCl $1,15 \%$ e o sobrenadante incubado a $100^{\circ} \mathrm{C}$ por $15 \mathrm{~min}$ em um meio contendo ácido tricloroacético (TCA) e ácido tiobarbitúrico. Após a incubação, o produto da reação foi extraído com álcool n-butílico e quantificado em $535 \mathrm{~nm}$. 
TABELA 1 - FORMULAÇÕES DOS PATÊS

\begin{tabular}{|c|c|c|c|c|}
\hline Ingrediente & $\begin{array}{c}\text { Controle } \\
\text { (formulação base) }\end{array}$ & $\begin{array}{l}\text { IAT } \\
18 \mathrm{mg}\end{array}$ & $\begin{array}{c}\text { IAT } \\
45 \mathrm{mg}\end{array}$ & $\begin{array}{l}\text { IAT } \\
90 \mathrm{mg}\end{array}$ \\
\hline Filé de pescado (g) & 280 & 280 & 280 & 280 \\
\hline Polpa de pescado (g) & 260 & 260 & 260 & 260 \\
\hline Água fria $(\mathrm{mL})$ & 200 & 190 & 175 & 150 \\
\hline Óleo de soja (mL) & 200 & 200 & 200 & 200 \\
\hline Proteína isolada de soja (g) & 15 & 15 & 15 & 15 \\
\hline Amido (g) & 20 & 20 & 20 & 20 \\
\hline Sal (g) & 18 & 18 & 18 & 18 \\
\hline Mistura de tempero $(\mathrm{g})$ & 6 & 6 & 6 & 6 \\
\hline Alho seco (g) & 2 & 2 & 2 & 2 \\
\hline Nitrito de sódio (g) & 1,5 & 1,5 & 1,5 & 1,5 \\
\hline Tripolifosfato de sódio (g) & 2 & 2 & 2 & 2 \\
\hline Fumaça líquida (mL) & 2 & 2 & 2 & 2 \\
\hline Corante carmim (mL) & 2 & 2 & 2 & 2 \\
\hline IAT 5\%* (mL) & - & 10 & 25 & 50 \\
\hline
\end{tabular}

* Infusão contendo 1,8 mg de compostos fenólicos/mL. IAT18 mg: 18 mg de fenólicos/kg de patê; IAT $45 \mathrm{mg}: ~ 45 \mathrm{mg}$ de fenólicos/kg de patê; IAT $90 \mathrm{mg}: ~ 90 \mathrm{mg}$ de fenólicos $/ \mathrm{kg}$ de patê.

A carbonilação de proteínas, determinada conforme Levine et al. (1994), foi avaliada como indicador da oxidação proteica. As amostras $(1 \mathrm{~g})$ foram homogeneizadas em solução salina tamponada, precipitadas com TCA e incubadas com dinitrofenilhidrazina no escuro durante 15 min. Em seguida, as amostras foram precipitadas em TCA e lavadas com uma mistura etanol/acetato de etila $(1: 1, v / v)$. O precipitado foi redissolvido em dodecilsulfato de sódio $2 \%$, e o conteúdo de grupos carbonila determinado em $370 \mathrm{~nm}$. Os resultados foram expressos em nmol de carbonil por mg de proteína. A quantificação de proteínas foi realizada seguindo o método de Lowry et al. (1951) pela leitura em $625 \mathrm{~nm}$ após reação com Folin Ciocalteu, utilizando albumina de soro bovino como padrão.

As coordenadas de cor dos patês foram avaliadas no sistema CIELab (1976) utilizando colorímetro CR-300 (Minolta Ltd., Osaka, Japão) com iluminante D65 e ângulo de observação de $2^{\circ}$, calibrado com uma placa padrão branca. Os patês foram espalhados em uma placa de Petri e foram realizadas três medições diretamente sobre as amostras. Os valores de $L^{*}$ indicam a luminosidade das amostras, valores de $a^{*} e b^{*}$ correspondem as coordenadas de cromaticidade, onde $+a^{*}$ representa a direção para o vermelho, $-a^{*}$ para o verde, $+b^{*}$ para o amarelo e - $b^{*}$ para o azul. Os valores de croma (C) expressam a saturação da cor e o ângulo de cor $(\mathrm{H})$ é a cor observada, expresso em graus: $0^{\circ}$ (vermelho), $90^{\circ}$ (amarelo), $180^{\circ}$ (verde) a $270^{\circ}$ (azul). 


\subsection{ANÁLISE ESTATÍSTICA}

Os dados foram analisados utilizando o programa Statistica ${ }^{\circledR} 9.1$ e foram expressos como média \pm erro padrão. Os resultados foram submetidos à análise de variância (ANOVA) em arranjo fatorial (4 formulações $\times 5$ tempos), e as diferenças entre as médias foram verificadas pelo teste de Tukey $(p<0,05)$.

\section{RESULTADOS E DISCUSSÃO}

A Tabela 2 mostra os resultados obtidos para o conteúdo de fenólicos totais da IAT $5 \%$ e a sua capacidade antioxidante in vitro. Estes resultados indicam que a $A$. triphylla possui elevado conteúdo de compostos fenólicos. Vaquero et al. (2010) constataram que a clarificação com carvão ativado em extrato aquoso de $A$. citriodora foi efetiva na remoção de compostos fenólicos, e ainda assim encontraram $533 \mathrm{mg}$ equivalentes de ácido gálico/L. Diversos estudos já demonstraram uma correlação positiva entre a quantidade de compostos fenólicos presente em infusões e extratos de folhas, frutas e sementes e a sua atividade antioxidante, comprovando que os compostos fenólicos são importantes contribuintes para a atividade antioxidante (LI et al., 2008; BAGETTI et al., 2009; 2011; HIRSCH et al., 2013). Corroborando estas evidências anteriores, a IAT $5 \%$ também se mostrou bastante efetiva na remoção do radical livre sintético DPPH (Tabela 2), apresentando atividade equivalente a uma solução contendo 3,2 mM de trolox, um análogo hidrossolúvel da vitamina $\mathrm{E}$.

\section{TABELA 2 - CONTEÚDO DE FENÓLICOS TOTAIS E ATIVIDADE ANTIOXIDANTE DE INFUSÃO DE ALOYSIA TRIPHYLLA (IAT)}

\begin{tabular}{lcc}
\hline & $\begin{array}{c}\text { Fenólicos totais } \\
\text { (mg ác. gálico/L) }\end{array}$ & $\begin{array}{c}\text { DPPH } \\
(\mathrm{mM} \text { trolox })\end{array}$ \\
\hline IAT 5\% & $1800,1 \pm 62,1$ & $3,2 \pm 0,8$ \\
\hline
\end{tabular}

Os resultados são apresentados como média \pm erro padrão $(n=3)$. DPPH: 1,1 difenil-2-picril-hidrazila.

Os valores de $\mathrm{pH}$ indicam a acidez de um produto alimentício, que pode fornecer um dado valioso sobre seu estado de conservação (SOARES, et al., 1998). A ANOVA revelou que não houve efeito da formulação nos valores de $\mathrm{pH}$ dos patês, mas apenas efeito do tempo de armazenagem refrigerada $(p<0,05)$. $\mathrm{O}$ valor médio de $\mathrm{pH}$ de todas as formulações de patê reduziu ao longo da armazenagem $(7,20 \pm 0,01$ no primeiro dia vs. $6,70 \pm 0,01$ no dia $28, p<0.05)$. Esses valores de $\mathrm{pH}$ estão próximos a faixa de $\mathrm{pH}$ na qual a carne de pescado apresenta máxima retenção de água, que é entre 6,5 a 7,0 (Lee, 1987). A carne de pescado apresenta menor conteúdo de glicogênio em comparação com as carnes bovina e suína, o que resulta em maior pH final após o abate (SOARES et al., 1998) e pode explicar o pH inicial elevado encontrado nos patês no presente estudo. Na verdade, valores de $\mathrm{pH}$ próximos a neutralidade são comuns em patês de pescado (MINOZZO et al., 2010). Em outros estudos avaliando a estabilidade de patês de pescado também foi observada a queda do $\mathrm{pH}$ ao longo da armazenagem. Minozzo et al. (2010) constataram diminuição no pH de patês feitos com carne de "flaminguinha" (Paralonchurus brasiliensis) ao longo dos 42 dias de armazenagem refrigerada ( 7,08 no primeiro dia vs 6,27 no dia 42, $\mathrm{p}<0,05)$. Essa queda no $\mathrm{pH}$ pode ser consequência do desenvolvimento de bactérias láticas. Estas bactérias psicotróficas, resistentes à ação do nitrito, competem com bactérias patogênicas e são comumente encontradas em embutidos cárneos embalados a vácuo e estocados sob refrigeração (FRANZ e HOLY, 1996). 
O índice de TBARS é utilizado no controle de qualidade de vários produtos, pois fornece informações a respeito do estado de oxidação e da predição de rancidez do alimento analisado (OSAWA et al., 2005; FOGAÇA et al., 2009). A IAT não influenciou a oxidação lipídica (TBARS) dos patês de pescado (dados não mostrados) e a ANOVA revelou apenas efeito do tempo de armazenamento sobre esta variável $(p<0,05)$. No primeiro dia de análise, o valor médio de TBARS para todas as formulações foi de $0,02 \pm 0,005 \mathrm{mg} \mathrm{MDA} / \mathrm{kg}$ de patê, aumentando aos 9 dias de armazenamento $(0,52 \pm 0,004 \mathrm{mg} \mathrm{MDA} / \mathrm{kg}$ de patê; $p<0,05)$. A partir do dia 15 até o dia 28 os valores de TBARS reduziram e mantiveram-se em 0,08 $\pm 0,01$ $\mathrm{mg} \mathrm{MDA} / \mathrm{kg}$ de patê. Estes resultados contrastam com os resultados descritos por Valentão et al. (2002), que demonstrou que a infusão de $A$. triphylla liofilizada remove radicais hidroxila, superóxido e também ácido hipocloroso, efeito que foi atribuído à presença de compostos fenólicos, tais como verbascosídeo e derivados da luteolina. A legislação brasileira não indica um limite de oxidação lipídica avaliado por TBARS para produtos de pescado. Al-Kahtani et al. (1996) sugerem que o pescado é considerado em bom estado para consumo, quando apresentar valores abaixo de $3 \mathrm{mg} \mathrm{MDA} / \mathrm{kg}$. Assim, pode-se sugerir que o tempo de armazenamento dos patês não foi longo o suficiente para que houvesse a produção de compostos secundários da oxidação lipídica, já que os valores de TBARS ficaram bem inferiores a este limite. Fato semelhante foi observado no estudo de Piccolo et al. (2014), que investigou os efeitos de extratos hidroetanólicos de semente de Eriobotrya japonica na oxidação lipídica de patês a base de carne de pescado armazenados refrigerados. Os resultados mostraram que nas concentrações testadas, os extratos não foram capazes de inibir ou reduzir as reações de oxidação.

A oxidação proteica nos patês de pescado foi estimada a partir da formação de grupos carbonila em proteínas (Figura 1; $p<0,05$ ). As EROs não estão envolvidas somente na oxidação lipídica, mas participam também da oxidação proteica (LUND et al., 2011). A carbonilação de proteínas, oxidação de grupos sulfidrila e formação de ligações cruzadas são alguns dos resultados da oxidação das proteínas (LUND et al., 2011). No presente estudo, a ANOVA revelou efeito significativo da interação tempo de armazenamento $x$ tratamento sobre a carbonilação de proteínas. A oxidação proteica aumentou ao longo do armazenamento $(p<0.05)$. Nos três primeiros tempos de análise, 1, 9 e 15 dias de armazenamento, não houve diferenças significativas entre as formulações tratadas com IAT e a controle. Entretanto, aos 21 e 28 dias de armazenamento os patês contendo $45 \mathrm{mg}$ e $90 \mathrm{mg}$ de fenólicos $/ \mathrm{kg}$, respectivamente, apresentaram valores de carbonilação proteica superiores ao controle (Figura 1; $p<0,05$ ). Esse resultado indica que a IAT aumentou a oxidação proteica dos patês.

Apesar de existirem evidências de que a oxidação proteica pode estar associada à oxidação lipídica (ESTÉVEZ et al., 2005), não observamos esta relação no presente trabalho, já que o aumento da carbonilação de proteínas nas formulações com IAT não foi acompanhado por um aumento nos níveis de TBARS. A capacidade dos compostos fenólicos atuarem como antioxidantes depende de fatores intrínsecos, como sua própria estrutura química, e de fatores extrínsecos, como a composição e as características do substrato, estágio e intensidade das reações oxidativas (LUND et al., 2011). Segundo ESTÉVEZ et al. (2005), o efeito dos compostos fenólicos de uma planta sobre a estabilidade oxidativa de um sistema alimentar pode ser afetado pelas condições de oxidação e características lipídicas do sistema, além da presença de tocoferóis e outras substâncias ativas que podem conduzir a efeitos antioxidantes ou pró-oxidantes. Este fato pode ter ocorrido neste estudo, onde a IAT contribuiu para o aumento da oxidação proteica. Esse resultado reforça a importância da avaliação de antioxidantes em modelos alimentares, pois ainda que a IAT tenha apresentado efeito antioxidante in vitro no ensaio de DPPH, in situ o efeito foi oposto, aumentando a oxidação proteica. 


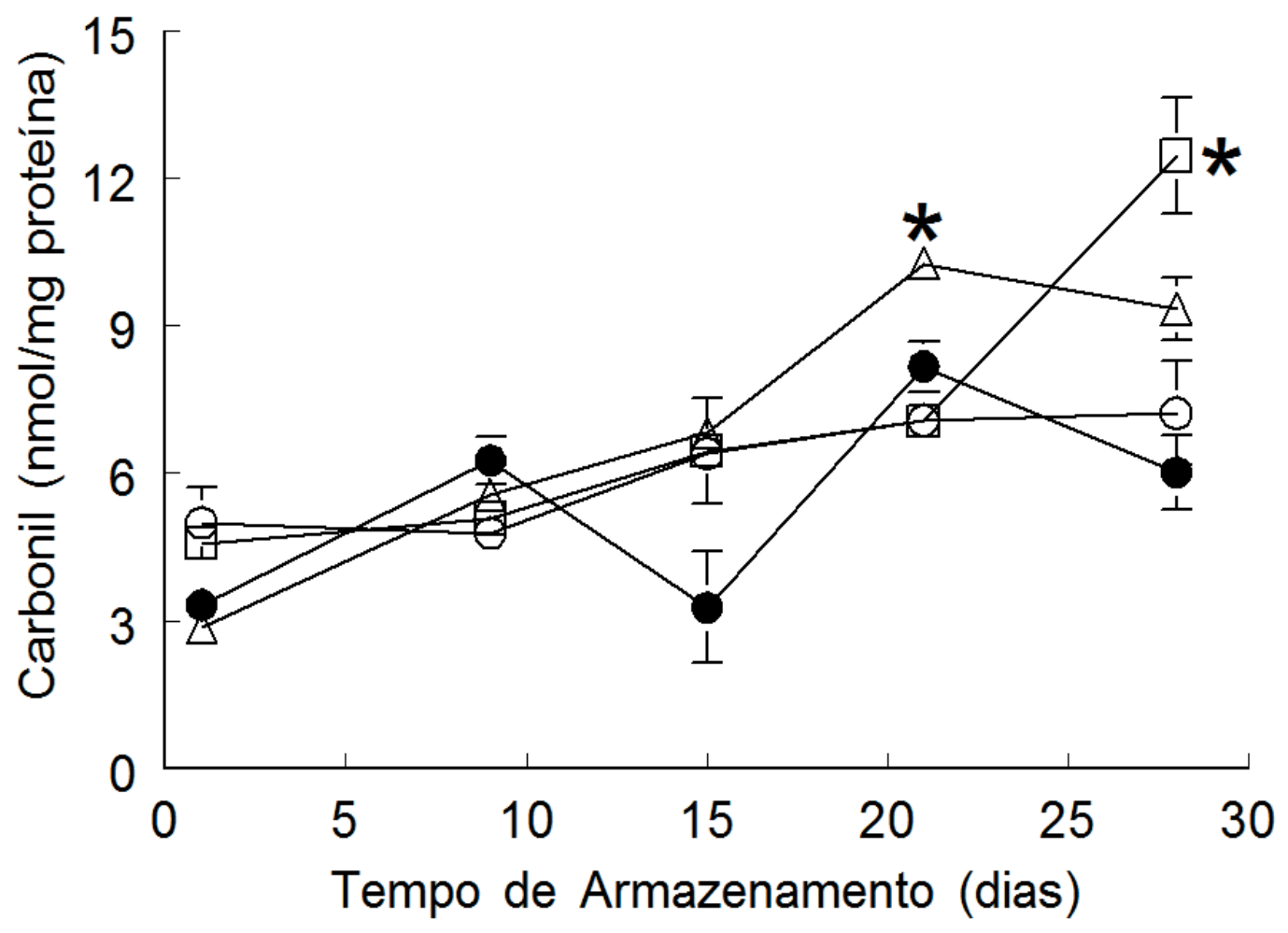

$\multimap$ Controle $\bigcirc$ IAT18mg $\triangle$ IAT45mg $\square$ IAT90mg

\section{FIGURA 1 - EFEITO DO TRATAMENTO COM INFUSÃO DE A. TRIPHYLLA (IAT) SOBRE A OXIDAÇÃO PROTEICA EM PATÊS DE PESCADO DURANTE ARMAZENAMENTO REFRIGERADO.}

Os valores são média \pm erro padrão $(n=3)$. A ANOVA revelou uma interação significativa tempo de armazenamento $x$ tratamento. *Significativamente diferente do controle no mesmo tempo de armazenamento refrigerado $(p<0,05)$. IAT18mg: $18 \mathrm{mg}$ de fenólicos/kg de patê; IAT45mg: $45 \mathrm{mg}$ de fenólicos $/ \mathrm{kg}$ de patê; IAT90mg: $90 \mathrm{mg}$ de fenólicos $/ \mathrm{kg}$ de patê.

Em relação às coordenadas de cor, a ANOVA revelou efeito significativo da interação formulação $x$ tempo de armazenamento sobre os valores de luminosidade $\left(L^{*}\right)$, tendência ao vermelho (cor $a^{*}$ ) e saturação da cor (croma) (Figura 2; $p<0,05$ ). O tempo de armazenamento teve efeito significativo sobre a tendência ao amarelo $\left(b^{*}\right)$ e o ângulo de cor $(H)$, sendo que este último também sofreu efeito do tratamento $(p<0,05)$, porém sem interação entre estes dois fatores.

No primeiro tempo de análise, todas as formulações contendo IAT apresentaram maior luminosidade (valores de $L^{*}$ ) que o controle (Figura $2 A ; p<0,05$ ). Porém, a luminosidade do controle aumentou do $1^{\circ}$ para o $9^{\circ}$ dia, quando a formulação contendo $18 \mathrm{mg}$ de fenólicos $/ \mathrm{kg}$ apresentou luminosidade inferior ao controle $(p<0,05)$. Durante o restante do tempo não foram observadas diferenças na luminosidade entre o controle e as formulações contendo IAT. Morkore (2006) sugere que o aumento de $L^{*}$ pode estar relacionado com alterações conformacionais de proteínas, que podem modificar a reflexão da luz incidente. As alterações na luminosidade podem estar relacionadas com a oxidação proteica que ocorreu, confirmada pelo aumento da carbonilação proteica ao longo do tempo do armazenamento. 

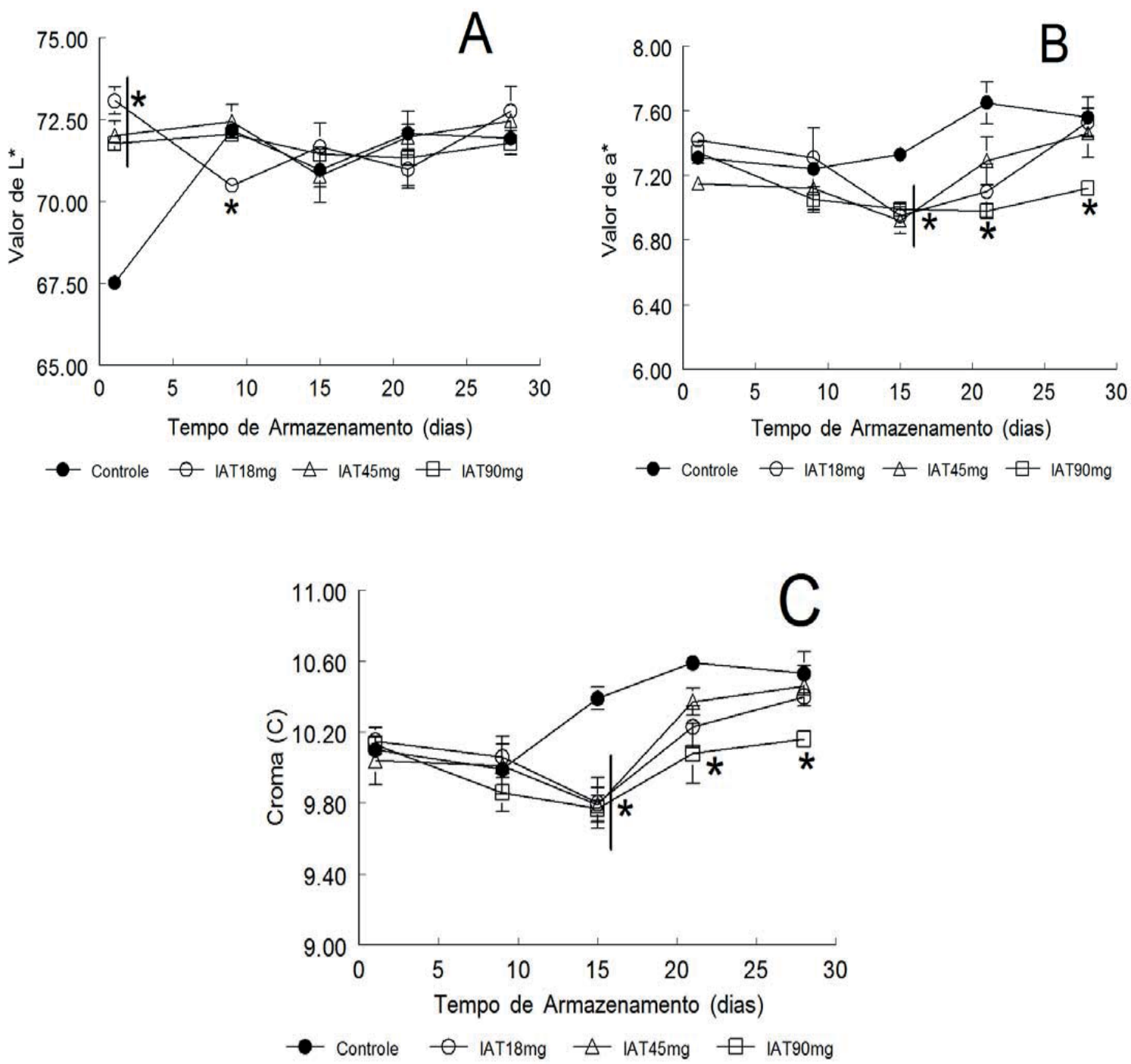

\section{FIGURA 2 - EFEITO DO TRATAMENTO COM INFUSÃO DE Aloysia triphylla (IAT) SOBRE AS COORDENADAS DE COR DE PATÊS DE PESCADO DURANTE ARMAZENAMENTO REFRIGERADO: L* (A), A* (B) E CROMA (C).}

Os valores são média \pm erro padrão $(n=3)$. *Significativamente diferente do controle no mesmo tempo de armazenamento refrigerado $(p<0,05)$. IAT18mg: $18 \mathrm{mg}$ de fenólicos $/ \mathrm{kg}$ de patê; IAT45mg: $45 \mathrm{mg}$ de fenólicos $/ \mathrm{kg}$ de patê; IAT90mg: $90 \mathrm{mg}$ de fenólicos $/ \mathrm{kg}$ de patê.

A adição de IAT reduziu a tendência ao vermelho (valores de $a^{*}$ ) e a saturação da cor (croma) dos patês em comparação ao controle no $15^{\circ}$ dia (formulações contendo $18 \mathrm{mg}, 45 \mathrm{mg}$ e $90 \mathrm{mg}$ de fenólicos $/ \mathrm{kg}$ de patê) de armazenamento refrigerado, mantendo-se este efeito até o $28^{\circ}$ dia para a formulação contendo $90 \mathrm{mg}$ de fenólicos $/ \mathrm{kg}$ de patê (Figura $2 \mathrm{~B} ; \mathrm{p}<0,05$ ). Esta mudança pode estar relacionada com a oxidação de pigmentos (hemoglobina e/ou mioglobina) presentes no patê, a qual pode influenciar na intensidade da coloração vermelha (HAMRE et al., 2003). O croma representa a intensidade da cor e é dependente dos valores de $a^{*}$ e $b^{*}$ na mesma proporção (RIBEIRO et al., 2007). Sua modificação parece estar associada à modificação dos valores de $a^{*}$, pois em todas as concentrações de IAT, nos mesmos dias de armazenagem e formulações em que houve redução da tendência ao vermelho, também ocorreu o decréscimo dos valores de croma.

A tendência ao amarelo $\left(b^{*}\right)$ aumentou para todos os tratamentos a partir do $21^{\circ}$ dia de armazenagem com relação ao tempo inicial $\left(6,97 \pm 0,12\right.$ no primeiro dia vs. $7,33 \pm 0,14$ no $21^{\circ}$ dia; 
$p<0,05)$, mas não foi modificada pela adição de IAT (dados não mostrados). O ângulo de cor $(H)$ dos patês foi influenciado pelo tratamento e pelo tempo de armazenamento $(p<0,05)$, sem interação entre estas variáveis. Os patés contendo $45 \mathrm{mg}$ de fenólicos $/ \mathrm{kg}$ apresentaram maior ângulo de cor que o controle $(43,7 \pm 0,84$ para o controle vs. $45,0 \pm 0,10$ para a formulação contendo $45 \mathrm{mg}$ de fenólicos/kg; $p<0,05$ ), por outro lado, a média do ângulo de cor de todas as formulações no $21^{\circ}$ dia foi superior ao $1^{\circ}$ e $9^{\circ}$ dia de armazenamento refrigerado $(43,5 \pm 0,56$ no primeiro dia, 43,9 $\pm 0,51$ no $9^{\circ}$ dia e $45,6 \pm 0,86$ no $21^{\circ}$ dia; $p<0,05$ ).

$\mathrm{O}$ uso de antioxidantes naturais como aditivos em alimentos é um dos diversos recursos para prevenir ou retardar as reações de oxidação lipídica e proteica. Assim, a adição de infusões ou extratos de plantas poderia estender a vida comercial de patês de pescado armazenados refrigerados e ser considerado como aditivo utilizado durante o processo de elaboração do produto. Porém, a IAT não promoveu efeito antioxidante nas condições do estudo realizado.

\section{CONCLUSÃO}

Apesar de ter apresentado atividade antioxidante no ensaio de remoção do radical DPPH in vitro, a infusão de $A$. triphylla, nas concentrações testadas, não promoveu alterações no $\mathrm{pH}$ e também não foi eficaz para prevenir a oxidação lipídica e proteica em patês de pescado. $O$ uso da infusão modificou significativamente as coordenadas de $\operatorname{cor} \mathrm{L}^{*}, \mathrm{a}^{*}$ e o croma dos patês, reduzindo a tendência ao vermelho, com relação ao controle, durante o armazenamento refrigerado. A discrepância entre os efeitos da infusão de $A$. triphylla no ensaio de remoção do radical DPPH e na estabilidade oxidativa de patês de pescado indica que este teste in vitro não é adequado para prever o potencial de antioxidantes neste tipo de alimento.

\section{ABSTRACT \\ ALOYSIA TRIPHYLLA INFUSION: OPPOSING EFFECTS ON AN IN VITRO ANTIOXIDANT ASSAY AND ON THE OXIDATIVE STABILITY OF REFRIGERATED FISH PATES}

The objective of this study was to evaluate the effect of Aloysia triphylla infusion (ATI) on the $\mathrm{pH}$ values and oxidative stability of fish pates (silver catfish, Rhamdia quelen) stored refrigerated. The ATI had $1.8 \mathrm{mg}$ total phenolics $/ \mathrm{mL}$ and good antioxidant capacity in the removal of the 2,2-diphenyl1-picrylhydrazyl (DPPH) radical (equivalent to a $3.2 \mathrm{mM}$ trolox solution). Fish pate formulations, which were a control pate (water) and three formulations containing increasing amounts of ATI (18 $\mathrm{mg}, 45 \mathrm{mg}$ and $90 \mathrm{mg}$ total phenolics $/ \mathrm{kg}$ pate), were stored at $5^{\circ} \mathrm{C}$ along 28 days to evaluate the $\mathrm{pH}$ value, lipid oxidation (thiobarbituric acid reactive substances, TBARS), protein oxidation (protein carbonyl groups), and the instrumental color (CIELab). The $\mathrm{pH}$ values were reduced along the storage, whereas the TBARS values increased up to the $9^{\text {th }}$ day of storage and then were reduced $(p<0.05)$, but these variables were not affected by the ATI ( $p>0.05)$. Protein oxidation increased along the storage $(p<0.05)$ and the fish pates containing $45 \mathrm{mg}$ and $90 \mathrm{mg}$ phenolics $/ \mathrm{kg}$ had higher protein carbonyl groups than the control at days 21 and 28 of storage, respectively $(p<0.05)$. Compared to the control formulation the ATI-containing ones had increased $L^{*}$ values in the beginning of the storage and reduced $a^{*}$ and chroma values from the $15^{\text {th }}$ day of storage onwards $(p<0.05)$. Despite having good activity in the in vitro antioxidant assay based on the DPPH removal, the ATI had no antioxidant effect in fish pates. 


\section{REFERÊNCIAS}

1 AL-KAHTANI, H. A.; ABU-TARBOUSH, H. M.; BAJABER, A. S. Chemical changes after irradiation and post-irradiation storage in tilapia and Spanish mackerel. Journal of Food Science, v. 61, n.4, p. 729-733, 1996.

2 ARAÚJO, J. M. A. Química de Alimentos: teoria e prática. 3. ed. Viçosa: UFV, 2004.

3 BAGETTI, M.; FACCO, E. M. P.; PICCOLO, J.; HIRSCH, G. E.; RODRIGUEZ-AMAYA, D.; KOBORI, C. N.; VIZZOTTO, M.; EMANUELLI, T. Physicochemical characterization and antioxidant capacity of pitanga fruits (Eugenia uniflora L.). Ciência e Tecnologia de Alimentos, v. 31, p. 147-154, 2011.

4 BAgETTI, M.; FACCO, E. M. P.; RODRIGUES, D. B.; VIZZOTTO, M.; EMANUELLI, T. Antioxidant capacity and composition of pitanga seeds. Ciência Rural, v. 39, p. 2504-2510, 2009.

5 BOCHI, V. C.; WEBER, J.; RIBEIRO, C. P.; VICTORIO, A. M.; EMANUELLI, T.Fishburgers with silver catfish (Rhamdia quelen) filleting waste. Bioresource Technology, v.99, p. 8844-8849, 2008.

6 BOtTERWECK, A. A. M.; VERHAGEN, H.; GOLDBOHM, R. A.; KLEINJANS J.; VAN DEN BRANDT, P. A. Intake of butilated hydroxyanisole and butilated hydroxytoluene and stomach cancer risk: results from analyses in the Netherlands cohort study. Food and Chemical Toxicology, v.38, p. 599-605, 2000.

7 BRAND-WILLIAMS, W.; CUVELIER, M. E.; BERSET, C. Use of a free radical method to evaluate antioxidant activity Lebensmittel-Wissenschaft und Technologie, v. 28, p. 25-30, 1995.

8 BUEGE, J. A.; AUST, S. D. Microsomal lipid peroxidation. Methods in Enzymology, v. 52, p. 302-309, 1978.

9 CARNAT, A., CARNAT, A. P.; FRAISSE, D.; LAMAISON, J. L. The aromatic and polyphenolic composition of lemon verbena tea. Fitoterapia. v. 70, n.1, p. 44-49, 1999.

10 CHAIJAN, M. Review: Lipid and myoglobin oxidations in muscle foods. Songklanakarin Journal of Science and Technology, v. 30, n. 1, p. 47-53, 2008.

11 DANIEL, A. P.; VEECK, A. P. L.; KLEIN, B.; FERREIRA, L. F.; CUNHA, M. A.; PARODI, T. V.; ZEPPENFELD, C. C.; SCHMIDT, D.; CARON, B. O.; HEINZMANN, B. M.; BALDISSEROTTO, B.; EMANUELLI, T. Using the essential oil of Aloysia triphylla (L'Her.) Britton to sedate silver catfish (Rhamdia quelen) during transport improves the chemical and sensory qualities of the fish during storage in ice. Journal of Food Science, v. 79, n. 6, p. 1205-1211, 2014.

12 ESTÉVEZ, M.; CAVA, R. Effectiveness of Rosemary essential oil as na inhibitor of lipid and protein oxidation: Contradictory effects in diferente types of frankfurters. Meat Science, v. 72, p. 348-355, 2006.

13 FLORA DIGITAL DE PORTUGAL. In: JARDIM BOTÂNICO DA UTAD. Disponível em: <http://aguiar.hvr.utad.pt.pt/ herbario/cons_reg_fam2.asp?familia=Verbenaceae\&ID=2240>. Acesso em: 16 jun 2014.

14 FOGAÇA, F. S. H.; SANT'ANA, L. S. Oxidação lipídica em peixes: Mecanismo de ação e prevenção. Archives of Veterinary Science, v. 14, n. 2, p. 117-127, 2009.

15 FRANZ, C. M. A. P.; HOLY, A.V. Bacterial populations associated with pasteurized vacuumpacked Vienna sausages. Food Microbiology, v.13, p.165-174, 1996.

16 FUNES, L.; FERNÁNDEZ-ARROYO, S.; LAPORTA, O.; PONS, A.; ROCHE, E.; SEGURA-CARRETERO, A.; FERNÁNDEZ-GUTIÉRREZ, A.; MICOL, V. Correlation between plasma antioxidant capacity and verbascoside levels in rats after oral administration of lemon verbena extract. Food Chemistry, v.117, p. 589-598, 2009.

17 HAMRE, K. LIE, O.; SANDNES, K. Development of lipid oxidation and flesh colour in frozen stored fillets of Norwegian springspawning herring (Clupea harengus L.). Effects of treatment with ascorbic acid. Food Chemistry, v.82, p.447-453, 2003.

18 HIRSCH, G. E. ; VIZZOTTO, M.; ABOY, A. L.; HENRIQUES, A. T.; EMANUELLI, T. Antioxidant activity of blackberry (Rubus sp.) genotypes from the Southern Region of Brazil. Boletim do Centro de Pesquisa e Processamento de Alimentos, v. 31, p. 83-98, 2013.

19 JARDINE, D.; ANTOLOVICH, M.; PRENZLER, P. D.; ROBARDS, K. Liquid chromatography-mass spectrometry (LCMS) investigation of the thiobarbituric acid reactive substances (TBARS) reaction. Journal of Agricultural and Food Chemistry, v. 50, n. 6, p. 1720-1724, 2002. 
modified proteins. Methods in Enzymology, v.233, p.346-357, 1994.

$22 \mathrm{LI}, \mathrm{H} . ;$ WONG, C.; CHENG, K.; CHEN, F. Antioxidant properties in vitro and total phenolic contents in methanol extracts from medicinal plants. LWT - Food Science and Technology , v. 41, p. 385-390, 2008.

23 LOWRY, D. H.; ROSEBROUGH, N. J.; FARR, A. L.; RANDALL, R. F. Protein measurement with the folin-phenol reagent. The Journal of Biological Chemistry, v. 93, p. 265-275, 1951.

24 LUND, M. N.; HEINONEN, M.; BARON, C. P.; ESTÉVEZ, M. Protein oxidation in muscle foods: A review. Molecular Nutrition \& Food Research, v. 55, p. 83-95, 2011.

25 MINOZZO, M. G. Patê de pescado: Alternativa para incremento da produção nas indústrias pesqueiras. 2010. 228 f. Tese (Doutorado em Tecnologia de Alimentos) - Programa de Pós-Graduação em Tecnologia e Alimentos, Universidade Federal do Paraná, Curitiba, 2010.

26 MINOZZO, M. G.; WASZCZYNSKYJ, N. Embutidos à base de tilápias. In: BOSCOLO, W. R.; FEIDEN, A. Industrialização de tilápias. Toledo, Paraná: GFM Gráfica \& Editora, 2007. p. 113-133.

27 MORKORE, T. Relevance of dietary oil source for contraction and quality of pre-rigor filleted Atlantic cod, Gadus morhua. Aquaculture, v.256, p.56-65, 2006.

28 OSAWA, C. C.; FELÍCIO, P. E.; GONÇALVES, L. G. Teste de TBA aplicado a carnes e derivados: métodos tradicionais, modificados e alternativos. Química Nova, v. 28, n. 4, p. 655-663, 2005.

29 PASTORIZA, L.;SAMPEDRO, G. Influence of ice storage on Ray (Raja clavata) wing muscle. Journal of Science of Food and Agriculture, v. 64, p. 9-18, 1994.

30 PICCOLO, J.; DANIEL, A. P.; KLEIN, B.; FERREIRA, L. F.; RUVIARO, A. R.; EMANUELLI, T.; KUBOTA, E. H. Oxidative stability of refrigerated fish patês containing loquat seed extract. Ciência Rural, v.44, n.9, p. 1705-1710, 2014.

31 RIBEIRO, S. C. A.; RIBEIRO, C. F. A.; PARK, K. J.; ARAUJO, E. A. F.; TOBINAGA, S. Alteração da cor da carne de mapará (Hypophthalmus edentatus) desidratada osmoticamente e seca. Revista Brasileira de Produtos Agroindustriais, $\mathrm{v}$. 9, n. 2, p.125-135, 2007.

32 RUFF, N.; FITZGERALD, R. D.; CROSS, T. F.; LYNCH, A.; KERRY, J. P. Distribution of $\alpha$-tocopherol in fillets of turbot (Scophthalmus maximus) and Atlantic halibut (Hippoglossus hippoglossus), following dietary a-tocopheryl acetate supplementation. Aquaculture Nutrition, v. 10, n. 2, p. 75-81, 2004.

33 SINGLETON, V. L. \& ROSSI, J. A. Colorimetry of total phenolics with phosphomolybdic-phosphotungstic acid reagents. American Journal of Enology \& Viticulture, v. 20, p. 144-158, 1965.

34 SOARES, V.F.M.; VALE, S.R.; JUNQUEIRA, R.G.; GLORIA, M.B.A. Teores de histamina e qualidade físico-química e sensorial de file de peixe congelado. Ciência e Tecnologia em Alimentos, v. 18, n. 4, 1998.

35 TREVIZOL, F.; ROVERSI, K.; DIAS, V.T.; ROVERSI, K. R.; PASE, C. S.; BARCELOS, R. C. S.; BENVEGNU, D. M.; KUHN, F. T.; DOLCI, G. S.; ROSS, D. H.; VEIT, J. C.; PICCOLO, J.; EMANUELLI, T. Influence of lifelong dietary fats on the brain fatty acids and amphetamine-induced behavioral responses in adult rat. Progress in Neuro-Psychopharmacology. $v$. 45, 215-220, 2013.

36 VAlENTÃO, P.; FERnANDES, E.; CARVALHo, F.; ANDRADE, P.B.; SEABRA, R. M.; BASTOS, M. L. Studies on the antioxidant activity of Lippia citriodora infusion: scavenging effect on superoxide radical, hydroxyl radical and hypochlorous acid. Biological and Pharmaceutical Bulletin, v 25, p. 1324-1327, 2002.

37 VAQUERO, M. J. R.; SERRAVALLE, L. R. T.; NADRA, M. C. M.; SAAD, A. M. S. Antioxidant capacity and antibacterial activity of phenolic compounds from argentinean herbs infusions. Food Control, v. 21, p. 779-785, 2010.

38 VEECK, A. P. L.; KLEIN, B.; FERREIRA, L. F. ; BECKER, A. G.; HELDWEIN, C. G. ; HEINZMANN, B. M.; BALDISSEROTO, BERNARDO ; EMANUELLI, TATIANA. Lipid stability during the frozen storage of fillets from silver catfish exposed to the essential oil of (Mill.) NE Brown. Journal of the Science of Food and Agriculture, v. 93, p. 955-960, 2013a.

39 VEECK, A. P. L.; BOLIGON, A. A.; ATHAYDE, M. L. ; EMANUELLI, T. Mate extract on lipid and color changes of dourado fillets during frozen storage. Ciência Rural, v. 43, p. 1317-1322, 2013b.

40 YURKO-MAURO, K. Cognitive and cardiovascular benefits of docosahexaenoic acid in aging and cognitive decline. Current Alzheimer Research, v. 7, 190-196, 2010.

41 ZAMORANO-PONCE, E.; MORALES, C.; RAMOS, D.; SEPÚLVEDA, C.; CARES, S.; RIVERA, P.; FERNÁNDEZ, J.; CARBALLO, M. A. Anti-genotoxic effect of Aloysia triphylla infusion against acrylamide-induced DNA damage as shown by the comet assay technique. Genetic Toxicology and Environmental Mutagenesis. Mutation Research, v. 603, p. 145-150, 2006. 


\section{AGRADECIMENTOS}

Este trabalho foi financiado pelo CNPq, Edital Casadinho/PROCAD (MCT/CNPq/MEC/ Capes). T. Emanuelli é bolsista de produtividade em pesquisa do CNPq. J. Piccolo recebeu bolsa de doutorado do CNPq. L.F. Ferreira e Bruna Klein receberam bolsas de iniciação científica PIBICCNPq/UFSM. 